\title{
ELECTROCARDIOGRAPHIC AND ECHOCARDIOGRAPHIC FINDINGS IN PATIENTS WITH CHRONIC OBSTRUCTIVE PULMONARY DISEASE ATTENDING A TERTIARY CARE HOSPITAL IN EASTERN INDIA: A CROSS SECTIONAL STUDY
}

\author{
Dr. Chinmoy Kumar Final Year Post Graduate Trainee, Department of General Medicine, \\ Ghosh \\ Burdwan Medical College Hospital.
}

Dr. Kumar Ābhishek Third Year Post Graduate Trainee, Department of General Medicine, Anand Burdwan Medical College Hospital.

\section{Dr. Pronoy Sen*}

Second Year Post Graduate Trainee, Department of Pulmonary Medicine, Burdwan Medical College Hospital. *Corresponding Author

ABSTRACT BACKGROUND: COPD is characterized by chronic airflow limitation and a range of pathological changes in the lungs. In addition, COPD presents significant extrapulmonary effects and is associated with important comorbidities that may contribute to the disease severity. COPD affects pulmonary blood vessels, right ventricle, as well as left ventricle leading to the development of pulmonary hypertension, cor-pulmonale, right ventricular dysfunction, and left ventricular dysfunction. This study was undertaken to evaluate cardiac function with ECG and echocardiography in COPD patients which may further help to assess the prognosis and identifying the individuals likely to suffer increase morbidity and mortality.

METHODS: An observational, cross sectional study was conducted among 100 patients attending the Department of General Medicine of Burdwan Medical College and Hospital, diagnosed as having COPD wherein detailed history taking and clinical examination was done along with routine investigations such as complete blood count, renal functions, randomized blood sugar and further for a Chest X-ray, electrocardiography, and two-dimensional (2D)-echocardiography. Statistical analysis was done by SPSS version 19.0.

RESULTS: Majority of the COPD patients were male and belonged to GOLD stage 2. The most electrocardiographic finding was P-Pulmonale and Echocardiographic finding was PAH (Pulmonary Arterial Hypertension) with maximum patients having mild PAH. Most common clinical finding was pedal edema. Severity of the disease was found to have linear relation with severity of cardiac complications.

CONCLUSION: There is significant involvement of the cardiovascular system in COPD patients. The electrocardiographic and echocardiographic findings had linear relation with the severity of the disease. It is mandatory to investigate all the COPD patients with ECG and 2D ECHO as it aids in early detection and treatment of cor pulmonale.

KEYWORDS : COPD, Echocardiography, ECG, Pulmonary Arterial Hypertension

\section{BACKGROUND:}

Chronic obstructive pulmonary disease (COPD) is a global health issue with smoking being the most important risk factor. By 2020, it will be the third most leading cause of mortality and fifth leading cause of morbidity in the world.[1,2] There is a crude estimate of about 30 million people in India suffering from COPD, and the death rate is among the highest in the world, data suggests that about 556,000 , i.e. ( $>20 \%$ ) of total $2,748,000$ die in India annually. $[3,4]$

COPD is characterized by chronic airflow limitation and a range of pathological changes in the lungs. In addition, COPD presents significant extrapulmonary effects and is associated with important comorbidities that may contribute to the disease severity. Chronic airflow limitation is associated with an abnormal inflammatory response of the lungs to noxious particles or gases, particularly cigarette smoke.[5]

COPD affects pulmonary blood vessels, right ventricle, as well as left ventricle leading to the development of pulmonary hypertension (PH), cor-pulmonale (COR-P), right ventricular dysfunction, and left ventricular dysfunction. Ischemic heart disease is one of the main causes of mortality in COPD.[6] Coexistence of both diseases is very common and has diagnostic, therapeutic, and prognostic implications.[7,8] Chronic bronchitis alone increases the risk of coronary deaths by $50 \%$. Reduced ratio of forced expiratory volume in $1 \mathrm{~s}$ (FEVI) to forced vital capacity (FVC) is also an independent risk factor for coronary events, increasing the risk by $30 \%$. With every $10 \%$ decrease in FEVl, all-cause mortality increases by $14 \%$ and an increase in cardiovascular mortality by $28 \%$.[9] In more advanced COPD, cardiovascular diseases account for $20-25 \%$ of all deaths.[10]
COR-P is defined as an alteration in the structure and function of the right ventricle caused by a primary disorder of the respiratory system. $\mathrm{PH}$ is the common link between lung dysfunction and the heart in COR-P. COR-P can develop due to various cardiopulmonary diseases. COR-P usually has a slow and chronic progression, but acute onset and life-threatening complications can occur.[11]

Echocardiography provides a rapid, noninvasive portable, and almost accurate method to evaluate the right ventricle function, right ventricular filling pressure, tricuspid regurgitation, left ventricular function, and valvular functions. It has been studied that echocardiography measured pulmonary arterial pressure closely correlates with pressure measured by right heart catheterization.[12]

This study was undertaken to evaluate cardiac function with ECG and echocardiography in COPD patients which may further help to assess the prognosis and identifying the individuals likely to suffer increase morbidity and mortality.

\section{METHODOLOGY:}

This institutional based cross sectional, observational study was included 100 consecutively selected COPD patients by convenience sampling admitted in General Medicine Ward of our Instituition over a period of 18 months. After approval from the Ethical Committee, Informed consent from each adult patient was taken. All the patients selected were asked for the detailed history of respiratory as well as cardiovascular symptoms and were clinically examined for the signs of ventricular hypertrophy, cardiomegaly, PH and/or heart failure. Patients were investigated for routine investigations 
such as complete blood count, renal functions, randomized blood sugar and further for a Chest X-ray, electrocardiography, and two-dimensional (2D)-echocardiography. All patients were subjected to resting two-dimension transthoracic Doppler echocardiography .

Echocardiography was done to assess the pericardium, valvular anatomy and function, left and right side chamber size and cardiac function. Tricuspid regurgitant flow was identified by colour flow Doppler technique and the maximum jet velocity was measured by continuous wave Doppler without the use of intravenous contrast. Right ventricular systolic pressure was estimated based on the modified Bernoulli equation and was considered to be equal to the SPAP in the absence of right ventricular outflow obstruction: sPAP $(\mathrm{mmHg})=$ right ventricular systolic pressure $=$ trans-tricuspid pressure gradient (TTPG) right atrial pressure (RAP), where trans-tricuspid gradient is $4 \mathrm{~V}(\mathrm{~V}=$ peak velocity of tricuspid regurgitation, $\mathrm{m} / \mathrm{s}$ ). RAP was empirically estimated as 15 $\mathrm{mmHg}$ before 1997. Since 1997, RAP was estimated to be 5, 10, or $15 \mathrm{mmHg}$ based on the variation in the size of inferior venacava with inspiration as follows: complete collapse, RAP $=5 \mathrm{mmHg}$; partial collapse, $\mathrm{RAP}=10 \mathrm{mmHg}$; and no collapse, RAP $=15 \mathrm{mmHg}$.[13] Pulmonary hypertension was defined in this study as $\mathrm{sPAP} \geq 30 \mathrm{mmHg}$. [14]This value was chosen according to the definition of $\mathrm{PH}$. $\mathrm{PH}$ was classified into mild, moderate, Severe and severe category as SPAP 3050, 50-70, >70 mmHg, respectively (using Chemla formula, mean pulmonary arterial pressure (MPAP) $=0.61$ PASP +2 $\mathrm{mmHg}$ and putting value of $25-35,35-45$, and $>45 \mathrm{mmHg}$ of MPAP for mild, moderate, and severe $\mathrm{PH}$, respectively). [14] Right ventricle dimension was measured by M-Mode echo and right ventricular dilation or cor pulmonale was said to be present when it exceeded the normal range of $0.9-2.6 \mathrm{~cm}$. Right ventricle contractility was also noted and right ventricular systolic dysfunction was said to be present when it was hypokinetic. Left ventricular function was also assessed by using the following parameters: EF (ejection fraction) is a measure of how much end-diastolic value is ejected from LV with each contraction ( $56 \%-78 \%$ ). FS (fractional shortening) is a percentage change in LV dimension with each LV contraction $(28 \%-44 \%)$. LV mass = left ventricular mass (88-224 g). $\mathrm{E} / \mathrm{A}=$ diastolic filling of left ventricles usually classified initially on the basis of the peak mitral flow velocity of the early rapid filling wave (E), peak velocity of the late filling wave caused by atrial contraction (A). In normal subjects LV elastic recoil is vigorous because of normal myocardial relaxation, therefore more filling is completed during early diastolic, so left ventricular diastolic dysfunction (LVDD) is said to be present when $\mathrm{E} / \mathrm{A}$ is $<1.3$ (age group $45-49$ years), <1.2 (age group $50-59$ years), <1.0 (age group $60-69$ years), and $<0.8$ (age group $\geq 70$ years). [15]

Inclusion criteria of the study included subjects between the age of 35-80 years with informed and written consent and diagnosed as a case of COPD by Spirometry. Exclusion criteria included cases of pneumonia, tuberculosis bronchial asthma, interstitial lung disease, carcinoma lung, any congenital heart disease, Left ventricular failure, Dilated cardiomyopathy. Descriptive statistical analysis of data has been done. The age and sex distribution of all patients, their body mass index (BMI), severity of COPD, echocardiography findings, the frequency of COR-P and its relation to COPD has been represented graphically. Correlation between the cardiac parameters on echocardiography findings and pulmonary parameters on spirometry findings have been done to find out the relation. The mean and standard deviation (SD) of FEVl and PH of all the patients has been calculated along with Pearson correlation value. Analysis was done with the help of SPSS version 19.0.

\section{RESULTS:}

Table 1: Sex Distribution of COPD patients aged above 35 years:

\begin{tabular}{|c|c|c|c|c|}
\hline Age & \multicolumn{2}{|c|}{ Male } & \multicolumn{2}{c|}{ Female } \\
\hline $\begin{array}{c}\text { Patients } \\
\text { above } 35 \\
\text { years of age }\end{array}$ & 72 & 72 & 28 & 28 \\
\hline No & \multicolumn{3}{|c|}{100 Patients } \\
\hline
\end{tabular}

Male cases were more in number than female. Male patients were $72 \%$ and female were $28 \%$ of total sample size respectively.

Table 2: GOLD staging of COPD:

\begin{tabular}{|c|c|c|}
\hline GOLD guideline & No of patients & Percentage \\
\hline Stage I (Mild) & $\mathbf{0 0}$ & $\mathbf{0 0}$ \\
\hline Stage II (Moderate) & 37 & 37 \\
\hline Stage III(Severe) & 33 & 33 \\
\hline Stage IV (Very Severe) & 30 & 30 \\
\hline Total & 100 & 100 \\
\hline
\end{tabular}

The patients diagnosed with COPD disease as per GOLD guideline, and we found maximum number of patients had stage II (Moderate) i.e $37 \%$, 33\% patients belonged stage III (Severe), $30.0 \%$ patients had stage IV (Very severe) and not a single patients had found in stage I (Mild).

Table3: Electrocardiographic finding of COPD patients

\begin{tabular}{c|c|c|c|c|c}
\multirow{2}{*}{ ECG Findings } & $\begin{array}{c}\text { Moderate } \\
\text { COPD } \\
(\mathbf{n}=37)\end{array}$ & $\begin{array}{c}\text { Severe } \\
\text { COPD } \\
(\mathrm{n}=33)\end{array}$ & $\begin{array}{c}\text { Very } \\
\text { severe } \\
\text { COPD } \\
(\mathbf{n}=30)\end{array}$ & $\begin{array}{c}\text { Total } \\
(\mathrm{n}=100)\end{array}$ & \multirow{2}{*}{ percentage } \\
\cline { 2 - 5 } No & No & No & No & \\
\hline p Pulmonale & 4 & 13 & 23 & 40 & 40 \\
\hline R/S in V1>1 & 2 & 9 & 12 & 23 & 23 \\
\hline R/S in V6<1 & 2 & 6 & 11 & 19 & 19 \\
\hline RAD & 4 & 3 & 4 & 11 & 11 \\
\hline RBBB & 0 & 3 & 4 & 07 & 07 \\
\hline AF & 0 & 1 & 3 & 04 & 04 \\
\hline VPC & 1 & 2 & 3 & 06 & 06 \\
\hline
\end{tabular}

The most common electrocardiographic finding is $\mathrm{P}$ Pulmonale $(40.0 \%)$ seen in most of the very severe group of COPD. The next common finding is $\mathrm{R} / \mathrm{S}$ inVl $>1$ found in 23.0 $\%$ and $\mathrm{R} / \mathrm{S}$ in $\mathrm{V} 6<\mathrm{l}$ found in $19.0 \%$. Right axis deviation alone was found in $11.0 \% .7 .0 \%$ had RBBB, $\mathrm{AF}$ was found in $4.0 \%$ and VPC was found in $6.0 \%$ in severe and very severe groups of COPD in the present study. All the ECG changes except right axis deviation and RBBB had significant relation with the severity of the disease. The insignificance of RAD, RBBB, AF and VPC may be attributed to small sample size of the study.

Table 4: Echocardiographic findings present in COPD patients:

\begin{tabular}{|c|c|c|c|c|c|}
\hline $\begin{array}{c}\text { Echocardiography } \\
\text { findlings }\end{array}$ & $\begin{array}{c}\text { Moderate } \\
\text { COPD } \\
(\mathbf{n}=37)\end{array}$ & $\begin{array}{c}\text { Severe } \\
\text { COPD } \\
(\mathbf{n}=33)\end{array}$ & $\begin{array}{c}\text { Very } \\
\text { severe } \\
\text { COPD } \\
(\mathbf{n}=30)\end{array}$ & $\begin{array}{c}\text { Total } \\
(\mathbf{n}=100)\end{array}$ & \multirow{2}{*}{ percentage } \\
\cline { 2 - 5 } PAH & 6 & No & No & No & \\
\hline RA dilatation & 5 & 17 & 27 & 57 & 57 \\
\hline RV dialation & 5 & 14 & 27 & 49 & 49 \\
\hline TR & 5 & 19 & 20 & 44 & 46 \\
\hline RVH & 5 & 9 & 20 & 34 & 34 \\
\hline IVMA & 1 & 5 & 12 & 18 & 18 \\
\hline LVH & 1 & 7 & 4 & 12 & 12 \\
\hline EF & 0 & 1 & 12 & 13 & 13 \\
\hline LV Dilatation & 0 & 1 & 8 & 09 & 09 \\
\hline LVDD & 0 & 2 & 4 & 07 & 07 \\
\hline
\end{tabular}

In the present study having 100 COPD patients, $71.0 \%$ had $2 \mathrm{D}$ ECHO findings and $29.0 \%$ had normal study. Of these 29 
patients, with normal ECHO, 4 had electrocardiocardiographic changes. 4 patients in the total study had absolutely normal ECG but had significant echocardiographic changes. The most common echocardiographic finding in the study was pulmonary artery hypertension observed in $57.0 \%$ followed by right atrial dilatation and right ventricular dilatation seen in $49.0 \% \& 46.0 \%$ of cases respectively. Right ventricular hypertrophy was found in $34.0 \%$ and inter ventricular septal wall motion abnormality is found in $18.0 \% .12 \%$ had left ventricular hypertrophy. $7.0 \%$ of the cases had left ventricular diastolic dysfunction. $44.0 \%$ of the cases had tricuspid regurgitation. $13 \%$ cases had EF and LV Dilatation also found ie $9 \%$. The findings of pulmonary arterial hypertension, right ventricular dilatation, right atrial dilatation, right ventricular hypertrophy and interventricular wall motion abnormality are found to have increased incidence with duration and severity of illness and found mostly in severe(stage-3 GOLD) and very severe(stage-4 GOLD) classes of COPD. The p values for 2D $\mathrm{ECHO}$ were calculated using Fissure $\mathrm{t}$ test. All the findings except LVH and LVDD had highly significant correlation with the severity of the disease, the incidence being high in very severe disease.

Table 5: Distribution of pulmonary artery hypertension in various stages of COPD

\begin{tabular}{|c|c|c|c|}
\hline $\begin{array}{c}\text { GOLD COPD } \\
\text { staging }\end{array}$ & $\begin{array}{c}\text { Mild PAH }(<30 \\
\mathbf{m m H g})\end{array}$ & $\begin{array}{c}\text { Moderate PAH } \\
(\mathbf{3 0}-\mathbf{5 0} \mathbf{m m} \text { Hg) }\end{array}$ & $\begin{array}{c}\text { Severe PAH }(>50 \\
\mathbf{m m ~ H g})\end{array}$ \\
\hline Stage II & 13 & 0 & 0 \\
\hline Stage III & 24 & 12 & 2 \\
\hline Stage IV & 12 & 10 & 16 \\
\hline Total & $49(49.0 \%)$ & $22(22.0 \%)$ & $18(18.0 \%)$ \\
\hline
\end{tabular}

In the present study $56.0 \%$ of cases had pulmonary artery hypertension (PAH) of which $49.0 \%$ had mild PAH, $22.0 \%$ had moderate $\mathrm{PAH}$ and $18.0 \%$ had severe $\mathrm{PAH}$.

Figure 1: Clinical profile of cor-pulmonale

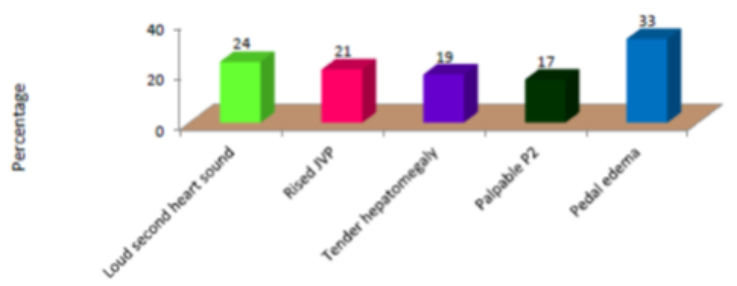

Pedal edema was the most common sign of cor pulmonale observed in $33.0 \%$ of patients. $24.0 \%$ had loud second heart sound, $21.0 \%$ had raised JVP, $19 \%$ had tender hepatomegaly and $17.0 \%$ had palpable P2.

\section{DISCUSSION:}

In our study males and females more than 35 years of age with history suggestive of chronic obstructive pulmonary disease. We have found male cases was higher than female. Male patients was $72 \%$ and female was $28 \%$ respectively. This in accordance with the study by Hideki Katsura et al.[16] where male : female ratio in COPD is approximately 3:1. In our study, maximum number of patients $37 \%$ diagnosed with COPD as per GOLD guideline had stage II disease(Moderate), 33\% patients belonged stage III (Severe), $30.0 \%$ patients had stage IV (Very severe) and not a single patients was found in stage I (Mild). We observed in the present study that, pedal edema was the most common sign of cor pulmonale observed in $33.0 \%$ of COPD patients. $24.0 \%$ had loud second heart sound, $21.0 \%$ had raised JVP, 19\% had tender hepatomegaly and $17.0 \%$ had palpable P2.The most common electrocardiographic finding is p Pulmonale (40.0\%) seen in most of the very severe group of COPD. $p$ values were calculated using fissure t test with $2 \times 3$ contingency table. All the ECG changes except right axis deviation and RBBB had significant relation with the severity of the disease. The insignificance for RAD RBBB, AF and VPC may be attributed to small sample size of the study. In the present study total 100 COPD patients, $71.0 \%$ had 2D ECHO findings and $29.0 \%$ had normal study. Of these 29 patients, with normal ECHO, 4 had electrocardiocardiographic changes. 4 patients in the total study had absolutely normal ECG but had significant echocardiographic changes. The most common echocardiographic finding in the study was pulmonary artery hypertension observed in $57.0 \%$ of cases followed by right atrial dilatation and right ventricular dilatation seen in $49.0 \%$ \& $46.0 \%$ of cases respectively. Right ventricular hypertrophy was found in $34.0 \%$ and inter ventricular septal wall motion abnormality is found in $18.0 \% .12 \%$ had left ventricular hypertrophy. $7.0 \%$ of the cases had left ventricular diastolic dysfunction. $44.0 \%$ of the cases had tricuspid regurgitation. The findings of pulmonary arterial hypertension, right ventricular dilatation, right atrial dilatation, right ventricular hypertrophy and interventricular wall motion abnormality are found to have increased incidence with duration and severity of illness and found mostly in severe(stage-3 GOLD) and very severe(stage-4 GOLD) classes of COPD. The $p$ values for 2D ECHO were calculated using Fissure $t$ test. All the findings except LVH and LVDD had highly significant correlation with the severity of the disease, the incidence being high in very severe disease. In the present study $56.0 \%$ had pulmonary artery hypertension (PAH) of which $49.0 \%$ had mild PAH, 22.0 $\%$ had moderate PAH and $18.0 \%$ had severe PAH. There is no exact data of PH prevalence in COPD; pulmonary artery pressures were seen elevated in about $20-90 \%$ of patients when measured by right heart catheterization, with evidence of changing severity in pulmonary hemodynamics with the severity in airflow obstruction.

Two studies by Kessler R. et.al and Oswald-Mamosser M. et.al have shown an abnormal increase in MPAP (Ppa) in COPD of $0.4-0.6 \mathrm{mmHg}$ per year. These studies illustrate that $\mathrm{PH}$ in COPD progresses slowly and occur in mild as well as severe forms of disease.[17,18] Study by Higham MA et.al demonstrated the 5 years survival rate being $50 \%$ in patients with mild PH (20-30 mmHg),30\% in those with moderate and severe $\mathrm{PH}(30-50 \mathrm{mmHg})$, and $0 \%$ in small group of patients suffering from severe $\mathrm{PH}$ ( $>50 \mathrm{mmHg}$ ). This study finding reveals $48 \%$ patients of varying severity of COPD have findings for $\mathrm{PH}$ that is almost similar to the previous studies. The frequencies of $\mathrm{PH}$ in moderate and severe COPD were $33.33 \%$ and $66.66 \%$,respectively which is comparable to other study in which findings were $43 \%$ and $68 \%$, respectively.[19] Previous studies showed the frequency of severe PH in COPD about $1-3 \%$ it has shown a high rise of $12 \%$ which could be explained as the study included only moderate and severe COPD cases. Approximately, about $25 \%$ patients of COPD develop COR-P.[29] One of the autopsies in a study by Gupta NK et.al showed $40 \%$ patients of COPD had COR-P.[20] The cause of LVDD in COPD patients could be due to chronic hypoxemia leading to the changes in myocardial relaxation, distension, and lung hyperinflation making the parietal pleura stiff and similarly the walls of cardiac fossa adding the load to the walls of ventricle and also due to ventricular interdependence. In our study, LVDD was present in $58 \%$ of patients as compared to $47.5 \%$ seen in the study done by Gupta NK et. al [21] Studies by Murphy ML et.al, Fluck DC et.al and Render ML et.al indicate that LV function remains normal in persons with COPD, whereas others suggest that LV dysfunction may be present. [22,23] Abnormal LV performance in persons with COPD may be due to a number of factors, such as hypoxemia and acidosis; concurrent coronary artery disease; ventricular interdependence (because the right 
ventricle (RV) and $L V$ share a common septum, RV dilatation may lead to bulging of the septum into the LV, which would in turn increase LV end-diastolic pressure, decrease venous return, and diminish LV stroke volume and cardiac output $(\mathrm{CO})$ and large swings in intrathoracic pressure (pronounced negative pleural pressure would increase Ppa and diminish LV stroke volume due to ventricular interdependence, negative pleural pressures may also increase LV after load).[24] Left ventricular systolic dysfunction (LVSD) is present in $7.5 \%$ patients, in previous studies by Vizza CD et.al, Jardin F et.al, Louridas $\mathrm{G}$ et.al and Funk GC et.al, it was present in 4\%-32\% patients of COPD.[25-28] LVDD was seen in COPD patients with normal pulmonary arterial pressure and it increased with right ventricular after load in a study by NK Gupta et.al.[29]Poddar AK et al, concluded[30] LVDD is present in $47.5 \%$ of patients, out of which 16 patients had $\mathrm{PH}$ and 3 did not have $\mathrm{PH}$, various mechanisms might explain the presence of left diastolic dysfunction in COPD patients. This may be due to chronic hypoxemia leading to abnormalities of myocardial relaxation, lung hyperinflation, and distension leading to increased stiffness of the parietal pleura and thus of the wall of cardiac fossa leading to added load on ventricle, and also due to ventricular interdependence. Left ventricular hypertrophy (LVH) was present in $22.5 \%$. In a study by Poddar AK et al , LVH was found in $25 \%-60 \%$ patients dying of COPD mainly in patients who also had right ventricular hypertrophy.[30]

\section{CONCLUSION:}

There is significant involvement of the cardiovascular system in COPD patients. The electrocardiographic and echocardiographic findings had linear relation with the severity of the disease. It is mandatory to investigate all the COPD patients with ECG and 2D ECHO as it aids in early detection and treatment of cor pulmonale.

To conclude, the present study shows high prevalence of pulmonary hypertension, cor pulmonale, left ventricular dysfunction complicating COPD, more so with severe COPD. We suggest screening of all COPD patients for cardiac complications. This would contribute to the assessment of prognosis in these patients and assist in identifying individuals likely to suffer increased mortality and morbidity warranting close monitoring and intense treatment.

\section{Limitations of this study :}

This study had a short time frame. So, long term follow up was not possible. It was also a hospital based study with a relatively small number of study population. Investigations like computed tomography or angiography were not incorporated in this study.

\section{REFERENCES}

1. Gunen H, Hacievliyagil SS, Kosar F, Mutlu LC, Gulbas G, Pehlivan E, et al. Factors affecting survival of hospitalised patients with COPD. Eur Respir J. 2005;26:234-41.

2. World Health Report. Geneva: World Health Organisation; 2000. [Last accessed on 2004 Jan].

3. Lopez AD, Shibuya K, Rao C, Mathers CD, Hansell AL, Held LS, et al. Chronic obstructive pulmonary disease: Current burden and future projections. Eur Respir J. 2006;27:397-412.

4. Salvi S, Agrawal A. India needs a national COPD prevention and control programme. J Assoc Physicians India. 2012;60:5-7.

5. GOLD. Global Strategy for the diagnosis, management, and prevention of chronic obstructive pulmonary disease: GOLD Executive Summary. [Last update on $2011 \mathrm{Feb} 21]$

6. Anthonisen NR, Skeans MA, Wise RA, Manfreda J, Kanner RE, Connett JE Lung Health Study Research Group. The effects of a smoking cessation intervention on 14.5-year mortality: A randomized clinical trial. Ann Intern Med. 2005;142:233-9.

7. Rutten FH, Moons KG, Cramer MJ, Grobbee DE, Zuithoff NP, Lammers JW, et al. Recognising heart failure in elderly patients with stable chronic obstructive pulmonary disease in primary care: Cross sectional diagnostic study. BMJ. 2005:331:1379

8. Rutten FH, Cramer MJ, Lammers JW, Grobbee DE, Hoes AW. Heart failure and chronic obstructive pulmonary disease: An ignored combination? Eur J Heart Fail. 2006;8:706-11.

9. Sin DD, Man SF. Chronic Obstructive Pulmonary Disease as a Risk Factor for Cardiovascular Morbidity and Mortality, Proceedings of the American
Thoracic Society, Vol.2, Symposium: Chronic obstructive pulmonary disease A disorder of the cardiovascular and respiratory systems. 2005:8-11.

10. Sin DD, Anthonisen NR, Soriano JB, Agusti AG. Mortality in COPD: Role of comorbidities. Eur Respir J. 2006;28:1245-57.

11. Weitzenblum E, Chaouat A. Cor pulmonale. Chron Respir Dis. 2009;6:177-85

12. Yock PG, Popp RL. Noninvasive estimation of right ventricular systolic pressure by Doppler ultrasound in patients with tricuspid regurgitation. Circulation. 1984:70:657-62.

13. Bredikis AJ, Liebson PR. The echocardiogram in COPD: Estimating right heart pressures. J RespirDis. 1998;19:191-8.

14. Chemla D, Castelain V, Humbert M, Hébert JL, Simonneau G, Lecarpentier Y, et al. New formula for predicting mean pulmonary artery pressure using systolic pulmonary artery pressure. Chest 2004:126:1313-7.

15. Libby P, Bonow RO, Zipes DP, Mann DL, editors. 8 th. Philadelphia: Saunders 2008. Braunwald's Heart Disease; p. 251.

16. Hideki KATSURA,Kouichi YAMADA, Ritsuko WAKABAYASHI AND Kozu KIDA.Gender-associated differences in dyspnea and health-relatedquality of life in patients with chronic obstructive pulmonary disease. Respirology (2007) 12, 427-432

17. Kessler R, Faller M, Weitzenblum E, Chaouat A, Aykut A, Ducoloné A, et al "Natural history" of pulmonary hypertension in a series of 131 patientswith chronic obstructive lung disease. Am J Respir Crit Care Med2001;164:219 24

18. Oswald Mammosser M, Weitzenblum E, Quoix E, Moser G, Chaouat A Charpentier $\mathrm{C}$, et al. Prognostic factors in COPD patients receiving long term oxygen therapy. Importance of pulmonary artery pressure. Chest 1995; 107:11938.

19. Higham MA, Dawson D, Joshi J, Nihoyannopoulos P, Morrell NW. Utility of echocardiography in assessment of pulmonary hypertension secondary to COPD. Eur Respir J 2001;17:350 5.

20. Rappaport E. Cor pulmonale. In: Murray JJ, Nadel JA, Mason RM, Boushey H, editors. Textbook of Respiratory Medicine. 4th ed. Philadelphia: W.B. Saunders; 2000. pp. 1631-48.

21. Gupta NK, Agrawal RK, Srivastav AB, Ved ML. Echocardiographic evaluation of heart in chronic obstructive pulmonary disease patient and its co relation with the severity of disease. Lung India 2011:28:1059

22. Murphy ML, Adamson J, Hutcheson F. Left ventricular hypertrophy in patients with chronic bronchitis and emphysema. Ann Intern Med. 1974;81:307-13.

23. Fluck DC, Chandrasekar RG, Gardner FV. Left ventricular hypertrophy in chronic bronchitis. Br Heart J. 1966;28:92-7.

24. Render ML, Weinstein AS, Blaustein AS. Left ventricular dysfunction in deteriorating patients with chronic obstructive pulmonary disease. Chest. 1995; 107:162-8

25. Vizza CD, Lynch JP, Ochoa LL, Richardson G, Trulock EP. Right and left ventricular dysfunction in patients with severe pulmonary disease. Chest. 1998;113:576-83.

26. Jardin F, Gueret P, Prost JF, Farcot JC, Ozier Y, Bourdarias JP. Two-dimensional echocardiographic assessment of left ventricular function in chronic obstructive pulmonary disease. Am Rev Respir Dis. 1984;129:135-42.

27. Louridas G, Patakas D, Stavropoulos C. Left ventricular function in patients with chronic obstructive pulmonary disease. Cardiology. 1981;67:73-80.

28. Funk GC, Lang I, Schenk P, Valipour A, Hartl S, Burghuber OC. Left Ventricular Diastolic Dysfunction in Patients With COPD in the Presence and Absence of Elevated Pulmonary Arterial Pressure. Chest. 2008;133:1354-9.

29. N. K. Gupta, Ritesh Kumar Agrawal, A. B. Srivastav, and M. L. Ved 'Echocardiographic evaluation of heart in chronic obstructive pulmonary disease patient and its co-relation with the severity of disease' Lung India. 2011 Apr-Jun; 28(2): 105-109.

30. Poddar AK, Chakraborti BN, Ghosh JL, Nandy S, Hazra S. Assessment of left ventricular function in patients of COPD :Ind J Tub. 1997;44:181 